\title{
Quem preserva tem! Preservação de acervo bibliográfico especializado na área agrícola
}

\author{
Rosângela Galon Arruda
}

\begin{abstract}
Bibliotecária - Sistema Embrapa de Bibliotecas. Mestre em Administração (UFSC)
\end{abstract}

http://dx.doi.org/10.1590/1981-5344/2351

Em uma época com imenso volume de informação disponível na internet, uma pergunta tem sido recorrente: por que preservar acervo bibliográfico geralmente antigo e ultrapassado? Porque as instituições investiram e investem em informação, por isso mantêm acervos impressos de grande relevância - por seu conteúdo e uso por parte de pesquisadores, estudantes e comunidade em geral - bem como por suas obras raras. Este trabalho apresenta a experiência relacionada ao desenvolvimento de um projeto para elaboração de uma política de preservação de acervo bibliográfico especializado na Empresa Brasileira de Pesquisa Agropecuária (Embrapa), que consistiu da elaboração de uma política de preservação de acervo bibliográfico para o Sistema Embrapa de Bibliotecas (SEB), seguida de uma campanha de divulgação com o slogan "Quem preserva tem!", que teve o objetivo de internalizar os cuidados necessários com o acervo. Além disso, o projeto possibilitou ainda a elaboração de um Manual de conservação preventiva e de uma Política de desenvolvimento de coleções.

Palavras-chave: Preservação de acervo; Desenvolvimento de coleções; Gestão da informação; Embrapa.

\section{Who preserves have! Specialized bibliographic collection preservation in agriculture}


In a time with huge amount of information on the Internet, one question has been recurrent: why preserve old and outdated bibliographic collections? Because institutions invested and invest in information, keeping printed collections of great relevance - for their content and use by researchers, students and community - as well as rare material. This paper presents the experience related to the development of a preservation project of specialized bibliographic collection in the Brazilian Agricultural Research Corporation (Embrapa), consisting in the elaboration of a preservation policy of bibliographic collection for Embrapa System of Libraries (SEB), followed by an campaign with the slogan "Who preserves have!", that hat the objective of internalizing the necessary care with the collection. Moreover, the project also made possible to elaborate a preventive conservation manual and a collection development policy.

Keywords: Collection preservation; Collection development; Information management; Embrapa.

Recebido em 05.03.2015 Aceito em 17.03.2016

\section{Introdução}

Para a preservação de acervo bibliográfico em bibliotecas, arquivos e museus são necessários conhecimento, monitoramento, medidas preventivas e curativas para evitar deterioração do material causada por agentes biológicos. Assim, a implantação de uma política de preservação, consiste em atestar valor ao que, como e onde precisa ser preservado em uma instituição. Consciente disso, a Embrapa aprovou o projeto Política de preservação de acervos, em 2009, que teve o objetivo de propor orientações gerais para a preservação de acervos bibliográficos e documentais. O termo política foi utilizado no sentido de reunir um conjunto de diretrizes e orientações sobre temas específicos na área de informação como desenvolvimento de coleções e preservação de acervos.

A Empresa Brasileira de Pesquisa Agropecuária (Embrapa), Empresa Pública fundada na década de 1970, possui um Sistema de Bibliotecas Especializadas que mantém acervos relacionados à missão de cada uma de suas 46 Unidades Descentralizadas, muitos originários ou herdados de Institutos de Pesquisa extintos. O acervo geral destas bibliotecas conta com cerca de 700 mil registros ao todo, sendo 200 mil de sua própria produção científica. Deste montante, cerca de 1.400 obras foram identificadas como raras ou especiais e encontram-se descentralizadas nos acervos de várias bibliotecas da Embrapa. Para esta identificação alguns fatores de suma importância foram considerados, entre eles o limite 
histórico, os aspectos bibliológicos, o valor cultural e a pesquisa bibliográfica.

Uma biblioteca especializada segundo Ashworth (1967) mantém acervo dedicado quase exclusivamente a publicações sobre um assunto determinado ou grupo de assuntos em particular. Desta forma, existem instituições que, por sua missão, possuem materiais únicos no país, ou seja, nenhuma outra instituição possui. Além disso, as instituições adquiriram por compra ou receberam de outros órgãos e instituições, publicações muito importantes para a pesquisa ou para a história da ciência, entre elas, coleções de obras raras. Neste trabalho conceituou-se obra rara como:

Todo documento difícil de ser obtido, por diversas circunstâncias, dentre as quais a antiguidade, tiragem reduzida ou escasso número de exemplares no mercado. Entre as obras raras, incluem-se os incunábulos, as obras publicadas entre os séculos XVI a XVIII, as publicadas na América antes de 1820, as edições limitadas e as de luxo, os exemplares únicos e os livros de associações com interesse particular (EMBRAPA, 1998).

Contudo, vivemos em uma época com imenso volume de informação disponível na internet e uma pergunta tem sido recorrente: por que preservar acervo bibliográfico geralmente antigo e ultrapassado? Percebemos que Com as facilidades de acesso à informação, possibilitadas pelo desenvolvimento das tecnologias de comunicação e informação (TICs), muitas pessoas enxergam os acervos bibliográficos e documentais impressos como um quadro antigo e ultrapassado, que precisa ser descartado para aproveitamento do espaço para outras necessidades.

\section{Mas por que preservar?}

Um livro carrega em si mesmo as marcas da sua produção, servindo como documento representativo dos processos utilizados na época para a transmissão de informações. É através destes acervos que resgatamos nossas histórias dispersas em fragmentos. No entanto, as informações contidas em acervos históricos que são de grande importância para a memória científica podem desaparecer ou perder seu valor por uso inadequado, falta de preservação e segurança. Considerando que na atualidade as bibliotecas são a soma de suas coleções, que podem ser de natureza e formas distintas, elas preservam a riqueza e a variedade de valores culturais, científicos, históricos e econômicos de uma sociedade (PINHEIRO, 2009a).

Neste contexto, de acordo com Lino, Hannesch e Azevedo (2008), entende-se que, a informação existente nos acervos, em todos os diferentes suportes sob a guarda de bibliotecas é matéria orgânica e, portanto, tem um tempo de vida delimitado. Diante deste fato, 
conservação e preservação devem ser entendidas como uma forma de garantir o acesso à informação pela sociedade presente e futura.

A conservação é compreendida como um conjunto de procedimentos práticos e preventivos que tem por objetivo melhorar o estado físico do suporte, aumentar sua permanência e prolongar-lhe a vida útil (SPINELLI, 2006). De forma mais abrangente, a preservação é direcionada para a elaboração de políticas, oferecendo subsídios para que o documento permaneça em condições físicas de utilização, considerando a adequação do ambiente, da armazenagem e do acesso de maneira geral, conforme Luccas e Seripierri (1995, p. 9) citados por Pinheiro et al. (2009b).

$\mathrm{Na}$ realidade, as ações de conservação precisam ser vistas como atividades inerentes e rotineiras dos serviços de bibliotecas, arquivos e museus, considerando que são a garantia para a manutenção e a longevidade dos acervos, no intuito de promover a gestão e a proteção do conhecimento nas instituições. E para garantir que essas atividades tenham continuidade, o desenvolvimento de uma política de preservação, por meio de um conjunto de diretrizes e normas se faz necessária (DIAS; PIRES, 2003).

Neste processo, um dos passos iniciais e mais importantes para a preservação de acervos é a análise da coleção. Com ela, o gestor passa a ter real posse do acervo: cada item se individualiza, e seu real valor torna-se conhecido. Esta etapa preliminar contribui para a tomada de decisão quanto às prioridades para a gestão e a segurança das coleções (FALCHETTI et al., 2006).

Na Embrapa, existem diferentes realidades envolvendo a dinâmica da gestão dos acervos bibliográficos, por isso apresenta-se, a seguir, um pouco deste contexto.

\section{As bibliotecas no contexto da Embrapa}

As atividades da área de informação e documentação na Embrapa remontam à fundação da Empresa, em meados da década de 1970. Desde então, foram criadas bibliotecas especializadas nas áreas temáticas dos diversos Centros de Pesquisa distribuídos no país. Essas bibliotecas trabalham de forma integrada e são responsáveis pela gestão do acervo bibliográfico da Empresa, formam o Sistema Embrapa de Bibliotecas (SEB).

O SEB tem como finalidade criar condições para o funcionamento sistêmico das bibliotecas pela coordenação e execução das atividades de gestão da informação e documentação científica e tecnológica da Empresa. Além de bibliotecas em 44 Unidades, duas delas não possuem biblioteca física, o SEB tem um órgão coordenador, localizado na Biblioteca da Sede da Embrapa, em Brasília, subordinada à Embrapa Informação Tecnológica, Unidade Descentralizada que coordena a Organização e Difusão da Informação Científica e Tecnológica da Empresa.

O acervo das bibliotecas que integram o SEB é constituído por publicações voltadas para a área agrícola e afins, com alto valor no âmbito da informação científica, tecnológica, histórica e memorialística 
relacionada à pesquisa no Brasil. A constituição deste acervo se deu, inicialmente, com a incorporação de obras de Instituições que precederam a Embrapa na pesquisa agropecuária, como por exemplo: Instituto de Pesquisa Agropecuária do Leste (IPEAL), anteriormente chamado Instituto Agronômico do Leste (IAL), em Cruz das Almas, Bahia; Instituto de Pesquisa Agropecuária do Norte (IPEAN), antes Instituto Agronômico do Norte (IAN), em Belém, PA; Instituto de Pesquisa Agropecuária do Nordeste (IPEANE), que deu origem a Embrapa Semiarido, Petrolina, PE; Instituto Nacional do Óleo, RJ, entre outras. Parte deste acervo é composto por obras que possuem características peculiares, que as tornam especiais, valiosas e, em certos casos, raras. Essas obras carecem de cuidado e atenção permanente, pois a simples mudança na umidade e temperatura do ar pode intensificar a atividade de micro-organismos, 0 que pode levar à deterioração dos documentos.

Em 2004, foram encontrados focos de contaminação por microorganismos no acervo da Biblioteca da Sede da Embrapa, em Brasília, e também em outras bibliotecas das Unidades Descentralizadas. A causa principal deste evento foi o elevado nível de umidade do ar em decorrência de um período de fortes chuvas. Conforme orientação da fitopatologista da Embrapa Recursos Genéticos e Biotecnologia, Dra. Araílde Fontes Urben, a primeira providência tomada foi análise do ar da biblioteca, que possibilitou a identificação de nove tipos de fungos nas amostras.

Apresentamos a seguir os tipos de fungos encontrados na Biblioteca da Sede da Embrapa e em outras Unidades Descenralizadas:

Quadro 1 - Fungos e os danos físicos que podem causar nas pessoas

\begin{tabular}{l|l}
\hline \multicolumn{1}{c|}{ Nome } & \multicolumn{1}{c}{ Danos físicos que causam nas pessoas } \\
\hline \hline 1) Aspergillus flavus & $\begin{array}{l}\text { asma brônquica, conjuntivite, prostração, inapetência. } \\
\text { Produz aflotoxinas que podem causar câncer hepático }\end{array}$ \\
\hline 2) Aspergillus niger & rinite e asma \\
\hline 3) Aspergillus ochraceus & $\begin{array}{l}\text { rinite, asma. Pode causar degeneração hialina e necrose } \\
\text { focal das células hepáticas (pesquisas realizadas em } \\
\text { ratos) }\end{array}$ \\
\hline 4) Cladosporium cladosporioides & $\begin{array}{l}\text { rinite, asma. Pode causar edema e hemorragias (teste } \\
\text { em coelhos) }\end{array}$ \\
\hline 5) Drechslera sp & rinite alérgica \\
\hline 6) Phyllosticta sp & rinite alérgica \\
\hline 7) Nigrospora sphaerica & rinite alérgica \\
\hline 8) Curvularia brachyspora & alergia respiratória, rinite alérgica e asma \\
\hline 9) Fusarium oxysporum & $\begin{array}{l}\text { rinite alérgica e asma. Pode causar edema e hemorragia } \\
\text { (teste em coelhos) }\end{array}$ \\
\hline
\end{tabular}

Fonte: URBEN (2004).

Além dos sintomas descritos no Quadro 1, os micro-organismos mencionados também podem causar irritação nos olhos, dor de cabeça, irritação de pele, náuseas, sonolência e fadiga.

Depois de identificados os fungos, iniciou-se uma ação emergencial de higienização do acervo e do ambiente, por meio dos seguintes procedimentos para higienização de livros e estantes, realizada com a 
ajuda de empregados responsáveis pela manutenção: limpeza livro por livro, para retirada dos micro-organismos com pano seco; em seguida com pano úmido em água com água sanitária a $10 \%$, e finalmente, com pano limpo e seco. Para o ambiente físico, a limpeza do piso, vidros e esquadrias foi realizada com solução de água sanitária a $10 \%$.

A partir das dificuldades encontradas durante esse processo constatou-se a necessidade da proposição de um projeto para elaboração de diretrizes para a conservação e preservação do acervo em todas as bibliotecas do SEB, ou seja, adoção de medidas preventivas para evitar situações desastrosas.

\section{0 projeto política de preservação de acervos da Embrapa}

O projeto Política de preservação de acervos da Embrapa foi submetido pelo SEB em 2009, no âmbito da carteira de projetos da instituição, sendo aprovado e implementado nos anos seguintes e concluído em dezembro de 2013. Os objetivos do projeto foram elaborar e implantar política de preservação de acervos na Embrapa, regulamentando assim ações para a conservação e preservação de acervos bibliográficos, além de validar critérios para a identificação de obras raras e especiais na Embrapa.

A metodologia aplicada ao desenvolvimento do projeto seguiu as seguintes ações:

a)diagnóstico do acervo: avaliação e seleção das coleções e do ambiente físico, higienização e análise de uso dos recursos bibliográficos das Unidades selecionadas;

b)validação de critérios para a identificação de obras raras e especiais na Embrapa;

c)capacitação da equipe: 1) Curso Livro Raro: formação e gestão de coleções bibliográficas especiais, 30/11 a 04/12/2009, Salvador, BA; 2) XVI Seminário Nacional de Bibliotecas Universitárias de $17 / 10$ a 21/10/2010, Rio de Janeiro - Oficina de preservação de acervos; 3) Workshop de Gestão da Informação na Embrapa - 29/11 a 03/12/2011, Brasília, DF - Oficina de preservação de acervos;

d)elaboração da política.

Inicialmente, a proposta foi realizar as atividades em seis bibliotecas selecionadas a partir dos problemas relatados pelos bibliotecários quanto ao estado dos acervos. Foram considerados prioritários aqueles casos nos quais, não sendo estabelecidas medidas imediatas para estabilização dos danos, haveria prejuízos para a integridade do material. Participaram as seguintes Unidades: Embrapa Uva e Vinho, Embrapa Amazônia Oriental, 
Embrapa Rondônia, Embrapa Gado de Corte, Embrapa Mandioca e Fruticultura e Embrapa Sede.

Para a avaliação e seleção do acervo ficou estabelecida a necessidade de criação de uma comissão de avaliação para verificação dos seguintes critérios propostos:

a)analisar o conteúdo dos documentos (autoridade/autor, precisão, imparcialidade, cobertura do assunto, convergência com os temas pesquisados na Unidade);

b)adequação ao usuário (idioma, grau de utilização), e com aspectos adicionais (características físicas, contribuição potencial);

c)descartar obras técnicas desatualizadas, publicações de caráter noticioso e efêmero; obras sem relevante valor histórico, geográfico, político ou cultural; material danificado e irrecuperável; material fotocopiado após a aquisição do original; e exemplares excedentes.

Definidos os critérios e diagnosticado o acervo, esses materiais poderiam ser remanejados para outras bibliotecas, descartados, restaurados ou apenas higienizados. Com a ajuda de comissões de seleção, composta por pesquisadores, alguns materiais foram remanejados ou descartados. Neste processo foi realizada higienização de todos os materiais, por meio de empresas especializadas contratadas, em algumas bibliotecas e sob a orientação dos próprios bibliotecários com auxílio de pessoal da manutenção, em outras.

Nesta etapa, verificou-se a necessidade de um instrumento que pudesse subsidiar o bibliotecário na tomada de decisão quanto à seleção dos materiais, o que resultou na elaboração de uma Política de desenvolvimento de coleções para a Embrapa, contendo também diretrizes para a gestão do acervo em bibliotecas especializadas.

Paralelamente ao desenvolvimento do projeto foram adquiridos equipamentos para monitoramento de temperatura e umidade, esterilizadores de ar e aparelhos de ar condicionado para os ambientes das bibliotecas, kit preservação (fitas e papéis especiais para pequenos reparos), além de materiais de proteção individual como máscaras, óculos, luvas e aventais.

Com os planos de ação em execução, iniciou-se a pesquisa e elaboração de um documento onde seriam descritos os itens principais que deveriam ser observados nas bibliotecas para a conservação dos acervos.

\section{A política de preservação de acervos}

Como o objetivo principal do projeto era a elaboração de uma política visando à regulamentação de ações necessárias para a 
conservação e preservação de acervos, foi imprescindível a busca na literatura por experiências semelhantes em outras instituições.

O planejamento e a elaboração da política de preservação exigiu o estabelecimento de critérios, decisões e prioridades que nortearam todo o processo. As ações foram propostas de forma corporativa, tendo como princípios: a preservação da informação para o futuro e provimento do acesso no presente, independentemente do formato no qual se apresente; - apoio à missão da Embrapa, com a preservação das informações necessárias a soluções de pesquisa, da memória da produção científica e tecnológica da instituição; bem como o alinhamento com as demais políticas da Embrapa; o atendimento de critérios de integridade e fidedignidade das informações, por meio das melhores práticas existentes em preservação de acervos documentais.

Como diretrizes gerais para a preservação de acervos da Embrapa destacam-se três itens fundamentais, conforme o documento orientador publicado pela Biblioteca Nacional: a observação dos espaços físicos, dos acervos e do acesso. Observar as normas e os padrões internacionais para projetos arquitetônicos; identificar as necessidades de conservação do prédio; acompanhar, diagnosticar e reavaliar periodicamente as condições ambientais (higienização, luminosidade, temperatura e umidade relativa do ar); realizar periodicamente a manutenção de condições de segurança, incluindo a prevenção contra furtos e atos de vandalismo; verificar a qualidade do ar das bibliotecas, arquivos e museus, por meio de análises químicas periódicas, tomando-se as providências necessárias para sua adequação; destinar espaço físico específico e adequado para a coleção de obras raras e especiais, bem como orientações sobre como identificar obras raras e ou especiais, de acordo com as áreas de interesse para a pesquisa na instituição.

Com relação ao acervo, a orientação é diagnosticar e monitorar periodicamente suas condições físicas; manter armazenamento e acondicionamento adequados aos suportes físicos de cada tipo de documento; promover práticas preventivas periódicas e orientações para a conservação das coleções; efetivar práticas de pequenos reparos nas coleções, bem como encaminhar as obras danificadas para encadernação e restauração, por técnicos especializados; e fazer triagem nas obras recebidas como doação, para verificar possíveis ataques de insetos, higienizá-Ias antes da inserção no acervo.

Para o acesso ao acervo, destacam-se os itens: orientar o manuseio do acervo impresso e multimeios com o objetivo de garantir sua conservação; manter a informação digital acessível e em boas condições; armazenar informações institucionais e científicas e tecnológicas digitais em repositório institucional, visando ao acesso e a preservação da memória institucional; transferir ou reformatar suportes de informação, conforme as necessidades identificadas; efetivar ações de preservação e segurança de obras raras e especiais; utilizar sinalização adequada para orientar o acesso ao acervo impresso, multimeios ou digital; e o estabelecer competências e responsabilidades. 
Depois de finalizada, a política de preservação de acervos foi compartilhada, validada e publicada, e em parceria com a Secretaria de Comunicação da Embrapa, foi elaborada uma campanha para preservação de acervos com o tema "Quem preserva tem!", chamando a atenção dos usuários para os cuidados com os livros por meio de materiais para distribuição em todas as bibliotecas da Empresa como: marcadores de livros, banner e folder.

A Política de preservação de acervos na Embrapa (EMBRAPA, 2014c) foi aprovada pela Resolução do Conselho de Administração no 136 de 11 de dezembro de 2013 e publicada no Boletim de Comunicações Administrativas (BCA), $n^{\circ} 2$ de 9 de janeiro de 2014, para institucionalização dos procedimentos em todas as bibliotecas das Unidades Descentralizadas, assim como a Política de desenvolvimento de coleções (EMBRAPA, 2014b) e o Manual de conservação preventiva (EMBRAPA, 2014a), disponíveis no Portal Embrapa.

Quanto aos procedimentos necessários para a preservação de acervos, foi elaborado o Manual de conservação preventiva do patrimônio documental da Embrapa (EMBRAPA, 2014a), no âmbito do Projeto Memória Institucional, que constitui um instrumento passível de utilização pela Embrapa e por outras instituições.

\section{Conclusão}

A proposta de projeto corporativo surgiu com o objetivo de sanar problemas identificados nos acervos de algumas bibliotecas, tendo como meta a formulação de diretrizes norteadoras para a prevenção de deterioração de recursos informacionais. Todas as Unidades participantes conseguiram obter melhoria com relação ao espaço físico e higienização do acervo, aquelas que mantêm obras especiais e raras conseguiram separá-las do acervo geral e foi possível adequar o ambiente e o tratamento necessário. No entanto, existem algumas Unidades que não possuem condições necessárias para manter o acervo especial ou raro, estas deverão encaminhar os materiais para a Biblioteca da Sede, para armazenamento e cuidados em futuro projeto.

De maneira geral, destaca-se a importância da gestão do acervo nas bibliotecas, ou seja, de se conhecer o valor do acervo - tanto do ponto de vista de seu conteúdo, como de sua representatividade e uso - e qual o impacto das perdas e danos para a coleção e para a instituição. Para isso, há necessidade de uma adequada gestão - identificar, selecionar e qualificar as coleções por meio de técnicas especiais, pois, além das especificidades de algumas obras, de seu valor científico e da beleza, há que se considerar valor histórico, cultural e econômico.

Assim, as atividades de preservação representam também a responsabilidade social das instituições e devem ser incentivadas permanentementepara a consequente melhoria dos ambientes, a qualificação e a conservação das coleções e a qualidade do acesso, resultando na expansão do tempo de vida das obras e na qualidade de vida de todos envolvidos. 
Como resultado do projeto, além da conscientização para as ações voltadas para a gestão e sustentabilidade dos acervos, foi identificada uma nova oportunidade de projeto, a "gestão das obras raras". Este projeto deverá ter como principais objetivos, a centralização de muitas dessas obras em espaço adequado de armazenagem e tratamento; a digitalização de algumas delas para disponibilização na internet; a confecção de catálogos e a realização de exposições.

O trabalho de preservação de acervo é minucioso, requer atenção especial e uma visão crítica por parte dos profissionais responsáveis, necessita de métodos de avaliação, prevenção e correção no tratamento dos acervos. Para isso, há necessidade de capacitação dos profissionais quanto às técnicas necessárias de conservação e prevenção, de investimento da instituição na melhoria dos ambientes físicos, no sentido de reforçar também a responsabilidade do usuário no processo.

\section{Referências}

ASHWORTH, W. Manual de bibliotecas especializadas e de serviços informativos. Lisboa : Calouste Gilbenkian, 1967.

DIAS, M. M. de K.; PIRES, D. Formação e desenvolvimento de coleções e serviços de informação. São Carlos: EdUSFCar, 2003.

EMPRESA BRASILEIRA DE PESQUISA AGROPECUÁRIA (EMBRAPA). Manual de informação e documentação. Brasília, DF,1998.

EMPRESA BRASILEIRA DE PESQUISA AGROPECUÁRIA (EMBRAPA). Manual de conservação preventiva do patrimônio documental da Embrapa. Brasília, DF, 2014a. Disponível em: <https://www.embrapa.br/seb/normas-emanuais >. Acesso em: 21 jun. 2016.

EMPRESA BRASILEIRA DE PESQUISA AGROPECUÁRIA (EMBRAPA). Política de desenvolvimento de coleções. Brasília, DF, 2014b. Disponível em: <https://www.embrapa.br/seb/normas-e-manuais >. Acesso em: 21 jun. 2016.

EMPRESA BRASILEIRA DE PESQUISA AGROPECUÁRIA (EMBRAPA). Política de preservação de acervos na Embrapa. Brasília, DF, 2014c. Disponível em: <https://www.embrapa.br/seb/normas-e-manuais>. Acesso em: 21 jun. 2016.

FALCHETTI, B. et al. Desbastamento: remanejamento, descarte, preservação, conservação e restauração de materiais. 2006. [Trabalho apresentado como requisito parcial para aprovação da disciplina Gestão de Coleções, Faculdade de Filosofia Ciências e Letras de Ribeirão Preto. Universidade de São Paulo, Ribeirão Preto, 2006].

Lino, L. A. da S.; HANNeSCH, O.; AZEVEdo, F. C. de. Política de preservação no âmbito do gerenciamento de coleções especiais: um estudo de caso no Museu de Astronomia e Ciências Afins. Disponível em: $<$ http://catalogos.bn.br/planor/documentos/Lucia Alves.pdf $>$. Acesso em: 8 abr. 2008. 
PINHEIRO, A. V. O livro raro: formação e gestão de coleções bibliográficas especiais. Rio de Janeiro, 2009a. [Apostila distribuída durante curso no Mosteiro de São Bento da Bahia, em Salvador].

PINHEIRO, M. I. da S. et al. Pela preservação da memória documental como uma garantia do acesso à informação, à memória e à cidadania. Revista ACB: Biblioteconomia em Santa Catarina, Florianópolis, v.14, n.2, p.513-530 jul./dez. 2009b. Disponível em: $<$ http://revista.acbsc.org.br/racb/article/view/694 >. Acesso em: 10 out. 2011.

SPINELLI, J. Diretrizes de preservação na Fundação Biblioteca Nacional. Rio de Janeiro: Fundação Biblioteca Nacional, 2006.

URBEN, A. F. Laudo fitossanitário do ar atmosférico da Biblioteca da Sede da Embrapa. Brasília, DF: Embrapa Recursos Genéticos e Biotecnologia, 2004. Digitado. 